\title{
無冠詞の所属的名詞句 $\left[\mathrm{N}^{1} \mathrm{de} \mathrm{N}^{2}\right]$ の容認可能性 (2)
}

\author{
属性を表すとき
}

瓜谷 望

\section{1. はじめに}

本稿は、「無冠詞の所属的名詞句」 $\left(\mathrm{N}^{1} \mathrm{de} \mathrm{N}^{2}\right.$ の形式をもち、 $\mathrm{N}^{1}$ が $\mathrm{N}^{2}$ に意味 的に所属し、かつ $\mathrm{N}^{2}$ が無冠詞1)の名詞句）の容認可能性に関する研究の第 2 部である。第1 部の瓜谷（2003）では事物を表す名詞句を取り上げたが、この 第 2 部では mirada de águila, anchura de espaldas, ambiente de fiesta, dolor de cabezaのように $\mathrm{N}^{1}$ de $\mathrm{N}^{2}$ が属性を意味するものを対象とする。

この第 2 部の目的は、属性を表す「無冠詞の所属的名詞句」の種類や特徵を 明らかにし、以下のような表現の容認可能性に関与する要因を探ることであ る。

(1) a. dolor de \{cabeza/muelas/barriga $\}$

b. ??dolor de $\{$ nariz/mano(s)

(2) a. anchura de espaldas/banda $\}$

b. ??anchura de \{coche/televisión \}

(3) a. nivel de \{enseñanza/ingresos/inteligencia/vida\}

b. ??nivel de \{pantano/orquesta/suelo\}

\section{2. 言語資料体の分析}

最初に、属性を表す「無冠詞の所属的名詞句」の種類や特徵を述べてみたい。 資料体 ${ }^{3)}$ から得た合計 255 例を分析すると、次のことが明らかになる。

1) mirada de águila が mirada の下位類とみなせるように、事物を表す表 現同様 ${ }^{4}$ 、属性を表す場合でも、 $\left[\mathrm{N}^{1} \mathrm{de} \mathrm{N}^{2}\right]$ は $\mathrm{N}^{1}$ の下位類と自然に解釈でき るものが多い。

2 ) 機能面の特徵としては、例えば、mirada de águila が対象となる人間を 「(鷘のように) 鋭い視線」の持ち主として特徵づけるように、属性を表す「無 冠詞の所属的名詞句」はどれも $\left[\mathrm{N}^{1}\right.$ de $\left.\mathrm{N}^{2}\right]$ 全体が対象（多くの場合、主語の 
指示対象）を特徽づける機能を有している。

3) さらに注目に值するのは、これらの特徴に加えて、属性を表す $\left[\mathrm{N}^{1} \mathrm{de}\right.$ $\mathrm{N}^{2}$ ]は、どれも「共通基準」と「区別特徴」の組合せとして分析できること である。 mirada de águila を例にとると、mirada〈視線〉は人間に共通する属 性なので、類としての人間の「共通基準」とみなせ、その基準に関して特定の 対象となる人物が「区別特徵」である águila〈鷲（のような鋭さ）〉によって 特徵づけられると解釈できる。同様に claridad de juicio では、「共通基準」は 類としての人間に共通する属性の juicio〈判断力〉で、claridad〈明晰さ〉が その基準に関して特定の人物を特徵づける「区別特徵」と考えられる。

なぜこのような「共通基準」と「区別特徵」が必要とされるのだろうか。 「対象を特徴づける」とは「他の対象と区別する」ことである。それには同種 の他の対象との比較が前提となる。そして比較には何について比較するかとい う比較の基準（対象間に共通する特徽）が不可欠である。だからこそ対象を特 徵づける機能を果たす属性は、その対象が所属する類に共通する基準（「共通 基準」)、つまり比較の基準と、その基準に関してその対象のみを区別できる特 徵（「区別特徵」）の両方を必要とするのだろう。属性を表す「無冠詞の所属的 名詞句」の場合、対象の特徵づけに必要な「共通基準」と「区別特徵」が異な る名詞として明示的に実現していると考えられる。

属性を表す「無冠詞の所属的名詞句」は、この「共通基準」と「区別特徴」 の出現順序から次の 2 つの大きなグループに分類することができる。

$\left\lceil\right.$ Grupo 1: $\mathrm{N}^{1}$ (共通基準) de $\mathrm{N}^{2}$ (区別特徴)」(80例)

mirada de águila, cargo de director, etc.

$\left\lceil\right.$ Grupo 2: $\mathrm{N}^{1}$ (区別特徵） de $\mathrm{N}^{2}$ (共通基準)」(175例）

anchura de espaldas, lesión de corazón, etc.

以下、それぞれのグループの特徵を述べてみたい。

\section{1. Grupo 1：[N'（共通基準） de $\mathbf{N}^{2}$ (区別特徵)] (80例)}

このグループの特徵は、mirada de águila, cargo de director のように「区別 特徵」が後置されることである。これらは、さらに [de $\mathrm{N}^{2}$ (区別特徴)］の意 味解釈から次の 2 つの下位グループに分類される。

1) 比喻比較表現 mirada de águila, etc. (52例)

2 ) 役割機能表現 cargo de director, etc. (28例) 


\subsection{1. 比噞比較表現 (52例)}

Grupo 1 で最初に取り上げるのは「比喻比較表現」で、[de $\mathrm{N}^{2}$ (区別特徵)] が「〜のような」と訳すことができ、 $\mathrm{N}^{2}$ が比喻や比較の対象と解釈できるも のである。

cara de ángel〈(天使のように) 善人そうな顔〉; cara de bulldog〈(ブルドッ クのように）怒った顔〉； cara de juez〈(裁判官のように）いかめしい顔〉; cara de perro〈(犬のように) 不機嫌な顔〉; cintura de avispa〈(蜂) のように 細いウエスト〉; hambre de lobo〈(狼のように) 腹ペこ〉; lágrimas de cocodrilo〈(ワニのような) そら涙〉; mirada de águila〈(篦のように) 鋭い 視線〉; ojos de carnero〈(羊のように) 悲しそうな目〉; paso de tortuga〈(亀 のように）のろい歩み〉; risa de conejo〈(ウサギのような) 作り笑い〉, etc. (37例)

これらの「比喻比較表現」は一般的に慣用表現で、その派生的意味は次の例 が示すように〈 $\mathrm{N}^{2}$ のような $\left.\mathrm{N}^{1}\right\rangle$ という直接的意味から派生する。

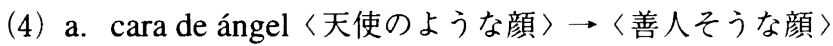

b. mirada de águila〈觜のような視線〉 $\rightarrow$ 〈鋭い視線〉

c. cintura de avispa〈蜂のような腰〉 $\rightarrow\langle$ 細い腰〉

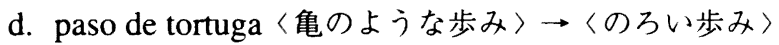

そしてこの派生的意味は多くの場合、程度副詞 muy を伴う品質形容詞で表 すこともできる。

(5) a. cara de ángel $\rightarrow$ cara muy bondadosa

b. mirada de águila $\rightarrow$ mirada muy aguda

c. cintura de avispa $\rightarrow$ cintura muy estrecha

d. paso de tortuga $\rightarrow$ paso muy lento

これは、比喻や比較の対象である $\mathrm{N}^{2}$ が程度化できる尺度的属性を含意する ためである。そして、その尺度的属性の高い值をもつ代表的な名詞が $\mathrm{N}^{2}$ とし て選ばれるのだろう。例えば、顔つきに〈極度の善良さ〉が見られる代表が ángel なので、cara de ángel が成立すると考えられる。同様に、視線にく極度 のするどさ〉を持つ代表が águila なので mirada de águila が、ウエストに 
〈極度の細さ〉を持つ代表が avispa なので cintura de avispa が、そして、歩み に〈極度の遅さ〉を持つ代表が tortuga なので paso de tortuga が、それぞれ比 喻表現として成り立つとみなせる。このように、この種の比喻比較の対象とし て選ばれる $\mathrm{N}^{2}$ は程度の高い属性を含意する代表的な名詞となっている。

また、「比喻比較表現」のもう一つの特徴として、mirada de águilaにおけ る〈鋭どさ〉、cintura de avispaにおける〈細さ〉、paso de tortugaにおける 〈遅さ〉というように、それぞれの尺度的属性は $\mathrm{N}^{2}$ として選ばれる名詞が含 意する様々な意味特徵の一側面のみに焦点を当てていることも指摘できる。

これに対して、 $\mathrm{N}^{2}$ が比喻や比較対象を表しているが、慣用性が低く、意味 の透明性が高い、次のような「比喻比較表現」もある。

ambiente de familia; apariencia de mendigo; azul de mar; cadencia de tango; cara de español; ojos de abuela; vida de eremita; vida de matrimonio, etc. (15例)

また、cara de ángel のような慣用性の高い「比喻比較表現」では、〈善良さ〉 等、比喻比較の対象である $\mathrm{N}^{2}$ が含意する意味特徵の「一側面」のみに焦点が あてられていたのに対して、apariencia de mendigoのように慣用性の低い 「比喻比較表現」では、 $\mathrm{N}^{2}$ が含意する意味特徵の「複合体」が「区別特徴」に なっている。例えば、 apariencia de mendigo で mendigo が含意する「区別特 徵」は対象となる人物の apariencia（共通基準）に見られる mendigoの〈複 合的視覚印象〉であり、cadencia de tango の「区別特徵」は cadencia を特徵 づける tangoの〈複合的音声特徵〉とみなすことができる。

以上が「Grupo 1: $\mathrm{N}^{1}$ (共通基準) de $\mathrm{N}^{2}$ (区別特徵)」の一番目の下位グル ープとしての「比喻比較表現」の特徵である。ある対象を特徵づけるにあたっ て、その対象が所属する類の「共通基準」に関して類似特徴をもつ別の対象に 喻えたり、比較することに特色があると言えよう。

\section{1. 2. 役割機能表現 (28例)}

$\left\lceil\right.$ Grupo 1: $\mathrm{N}^{1}$ (共通基準) de $\mathrm{N}^{2}$ (区別特徵)」の二番目の下位グループは、 cargo de director〈社長としての職〉ゃ cualidades de escritor〈作家としての

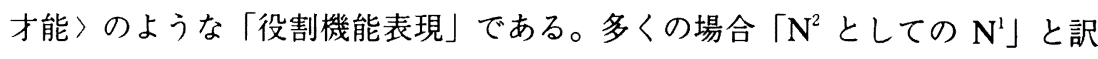
せるところに特徵がある。これらの $\mathrm{N}^{2}$ (区別特徴) は「役割機能」をもつも のと解釈できる。 
cargo de director; carrera de actriz; condición de abogado; cualidades de escritor; deber de estudiante; madera de escritor; oficio de pintor; papel de malo; rango de coronel; vocación de médico, etc. (28例)

「役割機能表現」は、対象となる人物を、人間に共通する属性（共通基準： cargo, cualidad, etc.) に関しての役割機能 (director, escritor, etc.) で特徵づ ける属性表現とみなすことができる。

\section{2. Grupo 2: N'（区別特幑） de $\mathbf{N}^{2}$ (共通基準)}

すでに述べたように、属性を表す「無冠詞の所属的名詞句」は「共通基準」 と「区別特徵」を表す 2 つ名詞の組合せとして実現する。そして、その組合 せの順序から「Grupo 1: $\mathrm{N}^{1}$ (共通基準) de $\mathrm{N}^{2}$ (区別特徵)」と「Grupo 2: $\mathrm{N}^{1}$ (区別特徵）de $\mathrm{N}^{2}$ (共通基準)」が区別された。Grupo 1 には、「比喻比較表現」 と「役割機能表現」の 2 つ下位グループがあり、両者の共通点は「区別特徵」 が後置されることだった。これに対して、次の Grupo 2 では、「区別特徴」が 前置されるところに特色がある。

Grupo 2 にも「区別特徵」の意味解釈から、2つの下位グループを区別でき る。

1) 指標表現 anchura de espaldas, claridad de juicio, etc.

2 ) 疾病表現 cáncer de pulmón, lesión de corazón, etc.

\section{2. 1. 指標表現}

「指標表現」は「Grupo 2: $\mathrm{N}^{1}$ (区別特徵) de $\mathrm{N}^{2}$ (共通基準)」の一番目の下 位グループで、 anchura de espaldas や nivel de enseñanza 等がある。anchura de espaldas が人間の「背中に関する長さの指標」であり、nivel de enseñanza が国民等の「教育程度に関する指標」とみなせるように、 $\mathrm{N}^{1}$ (区別特徵）と して、ある值をとる指標機能をもつ名詞が選ばれるところに特徵がある。資料 体では以下のような例が観察された。

anchura de banda, anchura de espaldas; anchura de pecho; capacidad de entendimiento; calidad de vida; contorno de cadera; cuota de mercado; densidad de población; grado de invalidez; índice de aridez; nivel de enseñanza; nivel de vida; punto de ebullición; tasa de desempleo, etc. (65例) 
「指標表現」は、対象を、その対象が所属する類に共通する「共通基準 $\left(\mathbf{N}^{2}\right) 」$

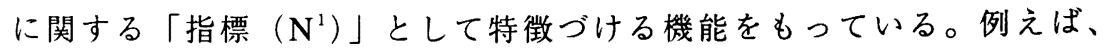
anchura de pechoは「人間等」(対象)を「胸：pecho」(共通基準)に関する 「長さの指標：anchura」(区別特徽）として特徵づける。同様に、cuota de mercadoは「製品等」(対象)を「市場：mercado」(共通基準)に関する「占 有率の指標：cuota」(区別特徵）として特徽づけ、densidad de poblaciónは 「国等」(対象）を「人口：población」(共通基準）に関する「密度の指標： densidad」として特徽づけると言えるだろう。

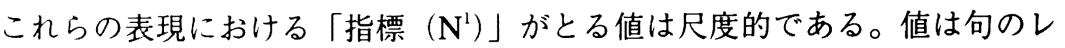
ベルでは未定だが、文脈によって決定される。例えば、anchura de pecho の值 は文脈を離れては決められないが、対象が特定の人物に決定すれば、值も $90 \mathrm{~cm}$ 等と決まることになる。

これに対して、「指標 $\left(\mathrm{N}^{1}\right) 」 の$ 值が、名詞自体の意味から含意されやすい 以下のような「指標表現」の例も存在する。

armonía de colorido; bajeza de ánimo; claridad de juicio; cortedad de ánimo; deficiencia de salud; destellos de inteligencia; dolor de cabeza; estrechez de espíritu; exceso de confianza; facilidad de palabra; grandeza de ánimo; limpieza de corazón, etc. (57例)

これらの表現における「指標 $\left(\mathrm{N}^{1}\right) 」$ の値は尺度的なだけでなく、高い程度 の值を含意しやすい。例えば、claridad de juicio〈判断の明晰さ〉における claridad や facilidad de palabra〈能弁さ〉における facilidad はそれぞれ〈高 い程度の明晰さ〉や〈高い程度の能力〉を含意しやすいと言えるだろう。

また、值の增減や変化を含意する以下のような「指標表現」もある。 alteración de salud; caída de color; caída de temperatura; cambio de imagen; deformación de imagen; degradación de color; subida de temperatura, etc. (13例)

subida de temperatura が対象（地域）を「共通基準（temperatura）」に関する 「数值的增加の指標（subida）」の值の上昇で特徴づけるように、これらの表現 では、対象を「共通基準 $\left(\mathbf{N}^{2}\right) 」 に$ 関する「指標 $\left.\left(\mathbf{N}^{1}\right)\right\rfloor$ の值の増減で特徴づ ける。

この他にも、値の異同の程度を問題にする次のような「指標表現」もある。 
afinidad de caracteres; conformidad de gustos; desnivel de fuerzas; diferencia de matices; diferencia de opinión; discrepancia de ideas, disparidad de cultos; distinción de edad; diversidad de caracteres; etc. (13例)

diferencia de opinión〈意見の違い〉が、対象（人間）を「共通基準 (opinión)」に関する「類似度の指標（diferencia）」で特徴づけるように、こ れらの表現では、対象を「共通基準 $\left(\mathbf{N}^{2}\right) 」 に$ 関する「指標 $\left(\mathbf{N}^{1}\right) 」$ の值の異 同の程度で表す。

以上、様々な「指標表現」を見てきた。これらの共通点は「指標 $\left(\mathbf{N}^{1}\right) 」 の$ とる値が尺度的で変動可能なことである。たとえば、 anchura de espaldas（背 中に関する長さの指標）、nivel de vida（生活に関する豊かさの指標）、 claridad de juicio（判断力に関する明晰さの指標）、caída de temperatura（気 温に関する数値減少の指標)、afinidad de caracteres（性格に関する類似度の 指標）等、どの指標の值も尺度的で、かりに同一の対象でも時間の経過に伴い 値が変化する可能性を秘めている。

これに対して、「指標表現」の中には非尺度的で固定的な值をとりやすい次 のようなものも存在する。

nombre de familia; número de teléfono; número de bastidor

lugar de nacimiento; estilo de vida; modo de vida; orden de palabras ( 7 例)

nombre de familia の值が、「田中、中村等」、número de teléfono の値が、 「110、119等」、lugar de nacimiento の值が「東京、静岡等」となるなど、こ れらの「指標表現」の值はどれも、非尺度的で、より固定的だと言えよう。

以上をまとめてみると、「Grupo 2: $\mathrm{N}^{1}$ (区別特徴) de $\mathrm{N}^{2}$ (共通基準)」の一 番目の下位グループである「指標表現」は、大多数が nivel de vida のように 尺度的で可変的な值をとる名詞句であること、また、相対的に少数だが nombre de familia のように非尺度的で、固定的な值をとる名詞句も存在する ことが明らかになった。

\section{2. 2. 疾病表現}

最後に、「Grupo 2: $\mathrm{N}^{1}$ (区別特徵) de $\mathrm{N}^{2}$ (共通基準)」の二番目の下位グル ープである「疾病表現」について簡単に触れてみたい。これらは、対象（人間 等）を共通基準である体の部分 $\left(\mathbf{N}^{2}\right)$ に関する病名等 $\left(\mathbf{N}^{1}\right)$ で特徵づける表 
現で、以下のようなものが観察された。

cáncer de mama; cáncer de pulmón; lesión de corazón; mal de hígado; calambre de estómago; infarto de miocardio; úlcera de estómago, etc. (20例)

「疾病表現」は、相対的に少ないことから、Grupo 2 のなかでは周辺的な位置 を占めていると言えそうである。

以上、資料体の 255 例を分析した結果、属性を表す「無冠詞の所属的名詞句」 は以下のように分類できることが明らかになった。

Grupo 1: $\mathrm{N}^{1}$ (共通基準) de $\mathrm{N}^{2}$ （区別特徵）

1)「比喻比較表現」 mirada de águila, etc.

2 )「役割機能表現」 cargo de presidente, etc.

Grupo 2: $\mathrm{N}^{1}$ (区別特徵) de $\mathrm{N}^{2}$ (共通基準)

1)「指標表現」 anchura de espaldas, etc.

2)「疾病表現」 cáncer de pulmón, etc.

\section{3. 属性を表す「無冠詞の所属的名詞句」の容認可能性}

この節では、上記の分類に基づいて、属性を表す「無冠詞の所属的名詞句」 の容認可能性について考察しよう。問題は、属性を表す表現 $\left[\mathrm{N}^{1}\right.$ de $\left.\mathrm{N}^{2}\right]$ がこ のどれかに分類できても、必ずしも容認可能性が高いとは判断されないことで ある。

例えば、次の例はどれも「Grupo 1: $\mathrm{N}^{1}$ (共通基準) de $\mathrm{N}^{2}$ (区別特徵)」に 属する「比喻比較表現」と分類できるだろう。

(7) a. velocidad de rayo

b. velocidad de tortuga

c. ??velocidad de gato

なぜ（7c）の容認可能性は低いのだろうか。「比喻比較表現」(2.1.1.) の説 明で、「比喻比較の対象として選ばれる $\mathrm{N}^{2}$ は程度の高い属性を含意する代表 的な名詞」だと述べた。この点、(7a) の rayo〈光線〉は〈極端な速さ〉を含 意する代表であり、(7b) の tortuga〈亀〉は逆に〈極端な遅さ〉を含意する代 表とみなすことができるだろう。これに対して、（7c) の gato〈猫〉は、速度 が中途半端で〈程度の高さ〉を含意しない。これが（7c）の容認可能性の低さ の原因と考えられる。では、なぜ〈程度の高さ〉が必要なのだろうか。これに はイメージ化の容易さに関係すると思われる。〈光線の速さ〉や〈亀の遅さ〉 
はある程度イメージしやすい。これに対して、〈猫の速度〉をイメージするの は難しい。歩く猫と走る猫でもだいぶ異なるだろう。つまり、イメージしやす い表現ほど、容認可能性が高まる傾向があると言えそうである。これは、瓜谷 （2003）で述べた「識別特徴の条件」が事物だけでなく、属性を表す「無冠詞 の所属的名詞句」の容認可能性の説明にも適用できることを示唆している。以 下にこの条件を再現してみよう。

\section{識別特徵の条件}

「無冠詞の所属的名詞句」([ $\mathrm{N}^{1}$ de $\left.\left.\mathrm{N}^{2}\right]\right)$ は、それが表す $\mathrm{N}^{1}$ の部分集合（種 類）を区別できる識別特徵が明白で、重要性も高いほど容認可能性が高い。

「識別特徵の条件」を先ほどの例に当てはめてみよう。velocidad de rayo, velocidad de tortuga, ??velocidad de gato はどれも属性 velocidad の下位類と 考えられる。velocidad de rayo と velocidad de tortugaには、〈極端な速さ〉 〈極端な遅さ〉等、それぞれの下位類を区別できる明白で重要な識別特徴があ る。これに対して、??velocidad de gatoは、下位類としての識別特徵が不明 確なために容認可能性が低いと説明できるだろう。つまり、〈猫の速度〉がイ メージ化しにくいのは明白な識別特徵がないためと考えられる。

次の例も同様に「識別特徴の条件」で説明可能だろう。

(8) a. cara de \{niño/juez/niño listo/niño asustado\}

b. ?? cara de $\{$ amigo/vecino/hermano/sobrino $\}$

（8a）は、cara de niño〈童顔〉, cara de juez〈いかめしい顔〉, cara de niño listo〈聡明な子の顔立ち〉, cara de niño asustado〈臆病な子の顔つき〉など、 それぞれ、cara〈顔つき〉の下位類としてどれもイメージしやすく、明白な識 別特徴が感じられる。また、これらの〈幼さ〉〈いかめしさ〉〈臆病さ〉などの 顔つきに関する諸特徵は人間を描写するためにしばしば言及される重要な特徵 でもある。

これに対して、容認可能性の低い（8b）の顔つきはどれも明白な識別特徵 がイメージしにくく、これらの特徵が人間を区別分類するために使用される可 能性は少ないと言えるだろう。

次の例でも「識別特徵の条件」は有効である。

(9) a. tengo dolor de \{cabeza/muelas/barriga $\}$

b. ??tengo dolor de $\{$ nariz/mano(s) $\}$ 
（9a）の dolor de cabeza〈頭痛〉, dolor de muelas〈歯痛〉, dolor de barriga 〈腹痛〉等の痛みの特徵はだれでも体験上想像しやすい。この意味で識別特徴 が明白な痛みと言えよう。また、これらの特徴は人間の健康状態の指標として たびたび使用される重要な特徴でもある。

これに対して、(9b) の痛みは、どれも一定の明白な特徵が感じられず、ま た健康状態の指標として使用される可能性も低い。これが容認可能性が低い原 因だと思われる。

それでは、次の例はどのように説明できるだろうか。「Grupo 2: $\mathrm{N}^{1}$ (区別特 徵） de $\mathrm{N}^{2}$ (共通基準)」に属する「指標表現」には、形態などの外見上の特徽 だけでは説明しがたい容認可能性の違いがしばしば存在する。

(10) a. anchura de \{espaldas/banda\}

b. ??anchura de \{coche/televisión\}

この例で、(10a) anchura de \{espaldas/banda $\}$ が (10b) anchura de \{coche/televisión\} よりイメージ的に明白だとは言えないだろう。瓜谷（2003） で指摘したように「識別特徵の条件」における $\mathrm{N}^{1}$ の部分集合（種類）を区別 できる明白で重要な識別特徵とは必ずしも形態などの知覚的印象に基づく特徵 のみでなく、用途や目的などの機能的特徵をも含んでいた。(10)の場合、形 態的特徽よりも機能的特徵が容認可能性の判断に影響を与えていると思われ る。なぜならば、すでに見たように属性を表す「無冠詞の所属的名詞句」 ([ $\mathrm{N}^{1}$ de $\left.\mathrm{N}^{2}\right]$ ) は対象をなんらかの形で特徴づける機能を持っていたが、この 機能的特徵が明白で、言及される頻度の高い重要なものほど容認可能性が高ま るという傾向があるからである。

例えば、(10a) の anchura de espaldas〈肩幅〉は、人間を体格の観点から 特徵づけたり、区別分類するための重要な基準としてょく使用される。対象と なる人間を $\mathrm{N}^{3}$ で表すと、espaldas が対象（人間 $=\mathrm{N}^{3}$ ) の共通属性である「共 通基準 $\left(\mathrm{N}^{2}\right)$ 」で、anchura $\left(\mathrm{N}^{1}\right)$ の值で対象 (人間 $\left.=\mathrm{N}^{3}\right)$ を区別分類する。 これを図式化すると以下のようになる。

- [la [anchura de espaldas (共通基準)] $\mathrm{de}^{3}$ (対象：人)]

同様に、anchura de banda〈周波数帯域幅〉も、ラジオ等の通信機器（対象 $\left(\mathrm{N}^{3}\right)$ ) を周波数の観点で特徵づけたり、区別分類するための重要な基準とし てよく使用される。この場合、banda が対象（ラジオ $=\mathrm{N}^{3}$ ) に共通する属性で ある「共通基準 $\left(\mathrm{N}^{2}\right)$ 」である。 
- [la [anchura de banda (共通基準)] de $\mathrm{N}^{3}$ (対象：ラジオ)]

これに対して（10b）の???anchura de coche〈車体の幅〉や??anchura de televisión〈テレビの幅〉が何を（対象 $\left(\mathbf{N}^{3}\right)$ ) を特徵づけたり、区別分類する ための基準として使用されるかわかりにくい。このことが（10b）の容認可能 性の低さの原因になっていると考えられる。

??[la [anchura de coche (共通基準? )] de $\mathrm{N}^{3}$ (対象：不明)］

このように、anchura の下位類の中でも、anchura de espaldas や anchura de banda など、その用途や機能（下位類の機能的識別特徵）が明白で、使用頻度 が高く、重要性が高い属性を表す表現ほど、容認可能性も高まると言えよう。 つまり「識別特徵の条件」はここでも有効なことがわかる。

以下の例も同様に説明できるだろう。

(11) a. nivel de $\{$ enseñanza/ingresos/inteligencia/vida $\}$

b. ??nivel de \{pantano/orquesta/suelo\}

(12) a. orden de palabras

b. ??orden de números

例えば、（11a）の〈教育レベル〉、〈所得レベル〉、〈知的レベル〉、〈生活レベ ル〉など容認可能性に問題のない $\left[\mathrm{N}^{1}\right.$ de $\left.\mathrm{N}^{2}\right]$ は、どれも国民等 $\left(\right.$ 対象 $\left(\mathrm{N}^{3}\right)$ ) を特徵づけたり、区別分類するための重要な基準としてたびたび言及される属 性である。

- [el [nivel de enseñanza (共通基準)] de $\mathrm{N}^{3}$ (対象：国民等)］

これに対して、（11b）の〈貯水池の水位〉、〈オーケストラのレベル〉、〈地 面のレベル〉など容認可能性の低い $\left[\mathrm{N}^{1}\right.$ de $\left.\mathrm{N}^{2}\right]$ は、何か $\left(\right.$ 対象 $\left.\left(\mathrm{N}^{3}\right)\right)$ を特 徵づけたり、区別分類するための基準として言及されることはあまりなさそう である。

-??[el [nivel de pantano（共通基準？)］ de $\mathrm{N}^{3}$ (対象：不明)]

同様に、(12a) orden de palabras〈語順〉は、SVO か SOV などの形式で、 英語、日本語等の言語（対象 $\left(\mathbf{N}^{3}\right)$ ) を特徵づけたり、区別分類するための重 要な基準となりうる。 


\section{- [el [orden de palabras (共通基準)］ de $\mathrm{N}^{3}$ (対象：言語名）]}

これに対して、（12b）??orden de números〈数字の順番〉によって区別分類 される対象 $\left(\mathbf{N}^{3}\right)$ は想定しがたく、したがって容認可能性も低い。

- ??[el [orden de números（共通基準?)] de $\mathrm{N}^{3}$ (対象：不明)]

それでは、次の例はどうだろうか。

(13) a. anchura de $\{$ espaldas/pecho\}

b. ??anchura de $\{$ muñeca(s)/muslo(s) $\}$

これらの例では、どれも人間（対象 $\left.\left(\mathrm{N}^{3}\right)\right)$ を体格の観点から区別分類するた めの基準とみなせなくもない。それでは、なぜ（13b）??anchura de muneca(s)〈手首のサイズ〉や??anchura de muslo(s)〈太股のサイズ〉は (13a)より容認可能性が低いのだろうか。

(13a) の anchura de espaldas〈肩幅〉と anchura de pecho〈胸囲〉は身体 測定の重要な基準として広く認められている。そのため、人間が〈肩幅〉や 〈胸囲〉によって特徴づけられたり、区別分類されることは珍しくない。これ に対して、〈手首のサイズ〉や〈太股のサイズ〉が人間の分類の基準に使用さ れることはまれである。このように、〈手首のサイズ〉や〈太股のサイズ〉は 一般的な身体測定の「重要な基準」とはみなされにくい。それが、これらの表 現の単独での容認可能性の低さの原因となっていると思われる。その証拠に、 これらの表現でも身体測定の重要な基準と解釈可能な文脈が与えられれば、容 認可能性が高まるからである。

(14) Para hacer unos pantalones ajustados, hace falta medir la anchura de muslos también.

以上から「Grupo 2: $\mathrm{N}^{1}$ (区別特徴) de $\mathrm{N}^{2}$ (共通基準)」に属する「指標表 現」においても、「識別特徵の条件」は適応可能であることがわかる。

瓜谷（2003）で「無冠詞の所属的名詞句」([ $\left.\left.\mathrm{N}^{1} \mathrm{de} \mathrm{N}^{2}\right]\right)$ は単なる $\mathrm{N}^{1}$ の下位 類ではなく、人間や社会にとって区別する価値の高い、重要な特徴をもつ下位 類を表すための表現だと指摘した。「無冠詞の所属的名詞句」はこのように重 要な下位類に言及する名称表現的性格をもつため、使用頻度が高く、固定表現 化しやすいと考えられる。この意味で、telaraña, bocacalle などの複合名詞に 通じるものがあると言えよう。下位類の重要性の判断は文化毎に異なる部分も あるが、人間の認知機構の共通性や人間社会の必要性の類似性に依存する部分 
も少なくないだろう。その意味で、容認可能性の高い「無冠詞の所属的名詞句」 と日本語の複合名詞に対応関係が見られる事実は興味深い。例えば、anchura de \{espaldas/pecho\} に対応する日本語の複合名詞として、「肩幅」と「胸囲」 が存在するのに対して、??anchura de \{muñeca(s)/muslo(s)\}に対応する 「?? 手首幅、? ? 手首囲」「? ? 腿幅、? ? 腿囲」はどれも不自然である。同 様に、dolor de \{cabeza/muelas/barriga\} に対応する日本語の複合名詞「頭痛」 「歯痛」「腹痛」が存在するのに対して、??dolor de \{nariz/mano(s)\}に対する 「? ? 鼻痛」「? ? 手痛」も奇妙である。このように、スペイン語の「無冠詞の 所属的名詞句」と日本語の複合名詞の容認可能性にある種の類似性が存在する ことは興味深い。

以上の考察から、「識別特徴の条件」は、事物のみでなく、属性を表す「無 冠詞の所属的名詞句」にも適用可能なことが明らかになった。

最後に、「独立性の条件」についても少しふれておこう。今回検討した属性 を表す「無冠詞の所属的名詞句」の255例 (mirada de águila, anchura de espaldas, ambiente de fiesta, dolor de cabeza, etc.) 全てにおいて、名詞 $\mathrm{N}^{2}$ が 特定の指示対象をもつことはない。これは、瓜谷（2003）で検討した「独立性 の条件」（特定の指示対象をもつ $\mathrm{N}^{2}$ に依存しない条件）が事物のみでなく、 属性を表す「無冠詞の所属的名詞句」にも適用できることを示唆していると思 われる。

\section{4. まとめ}

属性を表す「無冠詞の所属的名詞句」も、事物を表すもの同様、「識別特徵 の条件」を満たす程度が高いほど、その容認可能性が高まることが明らかにな った。

これは、「無冠詞の所属的名詞句」が人間や社会にとって区別する価值の高 い重要な下位類に与えられる名称表現であることの反映と解釈できる。

しかし、この問題はもう少し複雑で、重要な下位類を表す表現でもいつも名 詞 $\mathrm{N}^{2}$ が無冠詞になるとは限らない。次回の第 3 部（準備中）で、この問題に ついてさらに考察を深め、「無冠詞の所属的名詞句」の本質を探りたい。

\section{注}

* 本稿は、日本イスパニア学会第47回大会（2001年10月28日、天理大学）での口頭発 表「連体修飾語である前置詞句の無冠詞用法」に大幅に加筆修正を行ったものです。 
貴重なご意見を下さった先生方にこの場をお借りして心からお礼申し上げます。

1）より撖密に言えば、無冠詞の名詞と言うより限定詞のつかない名詞のことである。 限定詞に関しては、瓜谷（1995）参照。

2）属性と事物の区別は必ずしも明瞭ではない。そこで便宜上、tener の目的語の位置 で主語の指示対象の属性と解釈できるものを属性を表す「無冠詞の所属的名詞句」 とみなすことにする。(例：Juan tiene cara de niño.)

3）「無冠詞の所属的名詞句」の実態を探るために使用した資料体は前回と同じ『現代 スペイン語辞典 (改訂版)』白水社（1999）の見出し語と例文である。瓜谷（2003） p. 11 参照。

4）瓜谷（2003） p. 11 参照。

5） alto や viejo は対象である人間の「共通基準」である〈身長〉や〈年齢〉と、「区別 特徴」の〈基準より高い值〉が単一の語彙単位である形容詞として実現していると 解釈することもできる。安井（他）（1976）p. 75 を参照。

6）何が代表的な名詞となるかは多くの場合文化に依存すると考えられるだろう。 Bosque（1980）は否定文の解釈でこの種の名詞をスペイン文化の語用論的尺度の極 を占めるものと述べている。

7）これは claro, fácil など、〈基準より高い値〉を意味する形容詞が名詞化するときに おこる一般的な現象である。ライオンズ（1973）p. 520 参照。

\section{資料体}

宮城昇・山田善郎 (監)。1999,『現代スペイン語辞典（改訂版）」東京：白水社.

\section{引用文献}

Bosque, I. 1980, Sobre la negación, Madrid, Ediciones Cátedra, S.A.

ライオンズ、ジョン.1973,『理論言語学」國廣哲彌訳 東京：大修館書店.

瓜谷 望. 1995,「スペイン語限定形容詞の範囲」『語学研究』80, pp. 83-99.

瓜谷 望. 2003, 「無冠詞の所属的名詞句 $\left[\mathrm{N}^{1}\right.$ de $\left.\mathrm{N}^{2}\right]$ の容認可能性（1）事物を表すと き」『イスパニカ』47, pp. 10-24.

安井 稔 (他). 1976, 『形容詞 (現代の英文法第 7 巻)」東京：研究社. 
〈Resumen〉

\section{Aceptabilidad del sintagma nominal $\left[\mathrm{N}^{1}\right.$ de $\left.\mathrm{N}^{2}\right]$ con significado de pertenencia (2)}

\section{URITANI Nozomu}

Esta es la segunda parte del estudio sobre la aceptabilidad del sintagma nominal [ $\mathrm{N}^{\prime}$ de $\mathrm{N}^{2}$ ] que tiene significado de pertenencia y que no precisa de determinante en $\mathrm{N}^{2}$, siguiendo a Uritani (2003). En esta segunda parte tratamos sintagmas nominales $\left[N^{\prime}\right.$ de $\mathrm{N}^{2}$ ] que representan propiedad, como por ejemplo, "mirada de águila" o "anchura de espaldas", etc.

Nuestro estudio tiene por objeto, por una parte, clasificar tales sintagmas nominales y aclarar sus características examinando los datos de texto extraídos de un diccionario y ,por otra parte, explicar los factores que intervienen para determinar la aceptabilidad de sintagmas nominales del tipo, como por ejemplo:

(1) a. dolor de $\{$ cabeza/muelas/barriga $\}$

b. ??dolor de $\{$ nariz/mano(s) $\}$

(2) a. anchura de $\{$ espaldas/banda $\}$

b. ??anchura de \{coche/televisión \}

(3) a. nivel de \{enseñanza/ingresos/inteligencia/vida

b. ??nivel de \{pantano/orquesta/suelo\}

Los resultados de este análisis son los siguientes:

Estos sintagmas nominales $\left[\mathrm{N}^{1}\right.$ de $\mathrm{N}^{2}$ ] que representan propiedad, a diferencia de los que representan objetos, se pueden clasificar desde el punto de vista de la combinación de los nombres que significan "criterio común" y "rasgos distintivos".

Su aceptabilidad aumenta en proporción directa tanto al grado de claridad e importancia de sus rasgos distintivos como al grado de independencia entre el referente de $\mathrm{N}^{1}$ y el de $\mathrm{N}^{2}$, igual que en el caso de los sintagmas nominales $\left[\mathrm{N}^{1}\right.$ de $\mathrm{N}^{2}$ ]que representan objetos. Esto corrobora una vez más nuestra tesis de que los sintagmas nominales que tienen significado de pertenencia y que no precisan de determinante en $\mathrm{N}^{2}$ son expresiones usadas para denominar una subclase de entidades consideradas importantes para la comunidad linguística. 